\title{
Characterization of a Functional Role of the Bradyrhizobium japonicum Isocitrate Lyase in Desiccation Tolerance
}

\author{
Jeong-Min Jeon ${ }^{1}$, Hae-In Lee ${ }^{1}$, Michael J. Sadowsky ${ }^{2}$, Masayuki Sugawara ${ }^{2}$ and \\ Woo-Suk Chang $1,3, *$
}

1 Department of Biology, University of Texas, Arlington, TX 76019, USA; E-Mails: jeongm@uta.edu (J.-M.J.); hilee@uta.edu (H.-I.L.)

2 Department of Soil, Water \& Climate, and The BioTechnology Institute, University of Minnesota, St. Paul, MN 55108, USA; E-Mails: sadowsky@umn.edu (M.J.S.); msugawara@ige.tohoku.ac.jp (M.S.)

3 Division of Biotechnology, College of Environmental and Bioresource Sciences, Chonbuk National University, Iksan 570-752, Korea

* Author to whom correspondence should be addressed; E-Mail: wschang@uta.edu; Tel.: +1-817-272-3280; Fax: +1-817-272-2855.

Academic Editor: Jan Schirawski

Received: 28 June 2015 / Accepted: 20 July 2015 / Published: 22 July 2015

Abstract: Bradyrhizobium japonicum is a nitrogen-fixing symbiont of soybean. In previous studies, transcriptomic profiling of $B$. japonicum USDA110, grown under various environmental conditions, revealed the highly induced gene ace $A$, encoding isocitrate lyase (ICL). The ICL catalyzes the conversion of isocitrate to succinate and glyoxylate in the glyoxylate bypass of the TCA cycle. Here, we evaluated the functional role of B. japonicum ICL under desiccation-induced stress conditions. We purified AceA (molecular mass $=65 \mathrm{kDa}$ ) from $B$. japonicum USDA110, using a His-tag and Ni-NTA column approach, and confirmed its ICL enzyme activity. The ace $A$ mutant showed higher sensitivity to desiccation stress (27\% relative humidity $(\mathrm{RH})$ ), compared to the wild type. ICL activity of the wild type strain increased approximately 2.5 -fold upon exposure to $27 \%$ $\mathrm{RH}$ for $24 \mathrm{~h}$. The ace $A$ mutant also showed an increased susceptibility to salt stress. Gene expression analysis of aceA using qRT-PCR revealed a 148-fold induction by desiccation, while other genes involved in the glyoxylate pathway were not differentially expressed in this condition. Transcriptome analyses revealed that stress-related genes, such as 
chaperones, were upregulated in the wild-type under desiccating conditions, even though fold induction was not dramatic (ca. 1.5-2.5-fold).

Keywords: symbiotic nitrogen fixation; Bradyrhizobium japonicum; isocitrate lyase (ICL); ace A; desiccation stress

\section{Introduction}

Bradyrhizobium japonicum is a soil bacterium that has the ability to form nitrogen-fixing root nodules on soybean (Glycine max L.). Because of its symbiotic nitrogen-fixing ability B. japonicum has been considered one of the most important microorganisms in sustainable agriculture, as it can improve crop productivity with reduced use of nitrogen fertilizers for plant growth. A number of commercial inoculants of $B$. japonicum have been used for improvement of soybean yield [1]. However, the introduction of inoculants into field soils has not been always successful because of their low survivability under desiccating conditions [2]. Moreover, prolonged exposure to desiccation stress (e.g., drought) can adversely inhibit the nitrogen-fixing ability of B. japonicum [3].

Our previous functional genomics studies of B. japonicum showed that various stress-responsive genes, encoding heat shock proteins, chaperonins, or sigma factors, were induced by desiccation and desiccation-related stresses [4-6]. Interestingly, genes involved in oxidative stress response mechanisms were also induced, indicating that desiccation stress triggers other stress response mechanisms in rhizobia. Severe desiccation may also induce membrane shrinkage and alteration of electron transfer in membranes, leading to generation of reactive oxygen species (ROS). Our preliminary studies showed that there are overlapping gene expression profiles between oxidative and desiccation stresses (unpublished). Among them, aceA (blr2455) is of particular interest because it was highly induced under both stress conditions and the encoded protein isocitrate lyase (ICL) is a key enzyme in the glyoxylate pathway, a bypass of the tricarboxylic acid (TCA) cycle. In the glyoxylate cycle, ICL catalyzes the conversion of isocitrate $\left(\mathrm{C}_{6}\right)$ to succinate $\left(\mathrm{C}_{4}\right)$ and glyoxylate $\left(\mathrm{C}_{2}\right)$. Malate synthase (MS) subsequently catalyzes formation of malate $\left(\mathrm{C}_{4}\right)$ from glyoxylate $\left(\mathrm{C}_{2}\right)$ and acetyl-CoA $\left(\mathrm{C}_{2}\right)$ [7]. The glyoxylate cycle is necessary for bacteria to utilize two carbon $\left(\mathrm{C}_{2}\right)$ compounds, such as acetate, for fulfilling carbon requirements [8-10].

Several lines of evidence suggest that ICL has additional functions. Firstly, ICL was shown to be involved in bacterial responses to environmental stresses. The aceA gene was highly induced by high concentrations of salt in Shewanella sp. WP3 [11] and under low temperature in Colwellia maris [12]. Secondly, ICL is required for pathogenesis, persistence, and virulence in Mycobacterium tuberculosis [13,14]. Deletion of icl, a gene analogous to aceA, led to reduced persistence of M. tuberculosis in mice, indicating that ICL is essential for survival of this bacterium in the host $[14,15]$. Likewise, icl from the phytopathogenic fungus Leptosphaeria sp. was highly-induced during its infection of Brassica napus cotyledons, and inactivation of the gene resulted in low pathogenicity of the fungus due to its inability to utilize carbon sources provided by the plant [16].

Given the facts that the B. japonicum ace $A$ is induced by desiccation and oxidative stresses, and that the genes encoding ICL in other microorganisms are involved in stress tolerance and virulence, it is 
plausible that ace A may play a key role in the survival of $B$. japonicum under various environmental stresses, and perhaps protection of the bacterium from plant defense mechanisms, such as an oxidative burst, during infection.

Here, we performed genetic, transcriptomic, physiological, and phenotyping experiments to determine how ace $A$ responds to various stress conditions and how mutations of this gene affect survival and nodulation capacity of $B$. japonicum. In addition, through transcriptomic comparisons between the wild type and the aceA mutant, we determined whether ICL altered expression of other genes in this bacterium.

\section{Results}

\subsection{Purified AceA Has ICL Activity}

To confirm that AceA indeed has ICL enzyme activity, AceA was purified, to near homogeneity in a heterologous host, by using the His-tagging method. ICLs have been previously characterized in other microorganisms and ranged from $49-67.5 \mathrm{kDa}$ [13]. The AceA from B. japonicum USDA110 is comprised of 592 amino acids and has a predicted molecular mass of approximately $65 \mathrm{kDa}$. The size of the purified AceA was confirmed by SDS-PAGE (Figure 1). The purified AceA showed minor impurities (Figure 1), which might be due to frame shift during translation as in the case of the ICL homolog from M. tuberculosis [17]. The ICL activity of the purified AceA and intermediates during the purification is summarized in Table 1. Although the total activity of the purified AceA decreased by a factor of 360 , compared to that of the initial cell-free extract, the specific activity of AceA increased about 2.6 times as the protein amount decreased during purification steps (Table 1).

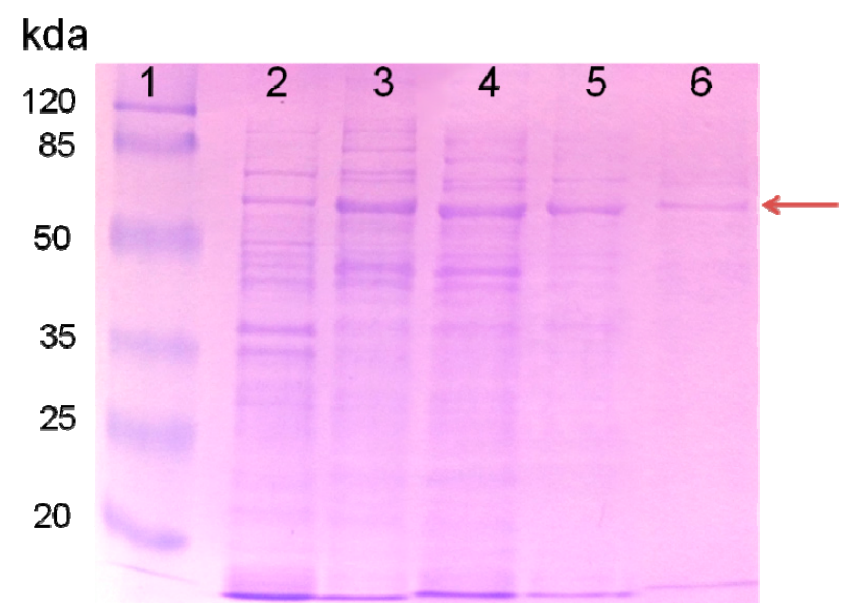

Figure 1. SDS-PAGE of the purified recombinant isocitrate lyase (ICL) protein. The arrow indicates the ICL protein. Lane 1, molecular mass markers (in $\mathrm{kDa}$ ); lane 2, whole cell extract of E.coli RIL (DE3) with control vector pQE2 before induction; lane 3, supernatant of induced E.coli RIL (DE3) containing recombinant pQE2 plasmid (pHis-aceA) after $0.1 \mathrm{mM}$ IPTG; lane 4, flow through sample after Ni-NTA column; lane 5, washed sample; and lane 6, purified ICL protein. The size of molecular mass markers is indicated on the left. 
Table 1. Purification of isocitrate lyase enzyme from recombinant Escherichia coli.

\begin{tabular}{cccc}
\hline Purification Steps & Soluble Protein (mg) & Total Activity (U) & Specific Activity (U/mg) \\
\hline Cell-free extract & 45.2 & 36.2 & 0.8 \\
Filtered on Ni-NTA column & 2.3 & 3.0 & 1.3 \\
Purified ICL protein & 0.04 & 0.1 & 2.1 \\
\hline
\end{tabular}

\subsection{The aceA Mutant WC2455 Is Sensitive to Desiccation and Salt Stress}

To investigate the role of aceA in resistance to desiccation, we compared the survival of wild type USDA110), the aceA mutant (WC2455), and the complemented strain (WC2455-C) under desiccation stress conditions. Under fully hydrated conditions (100\% relative humidity $(\mathrm{RH})$ ), all the strains tested did not show any significant difference in their survival rate (data not shown). In contrast, under desiccation conditions $(27 \% \mathrm{RH})$, strain WC2455 showed greater sensitivity to the desiccation stress than did USDA110 or WC2455-C (Figure 2A). The survival rate of WC2455 rapidly declined to about $20 \%$ after $3 \mathrm{~h}$ of desiccation exposure, whereas those of USDA110 and WC2455-C maintained a $\sim 60 \%-70 \%$ survival rate at this time point (Figure $2 \mathrm{~A}$ ). Viability of all tested strains decreased by more than $90 \%$ after $72 \mathrm{~h}$ exposure to desiccation stress (Figure $2 \mathrm{~A}$ ).

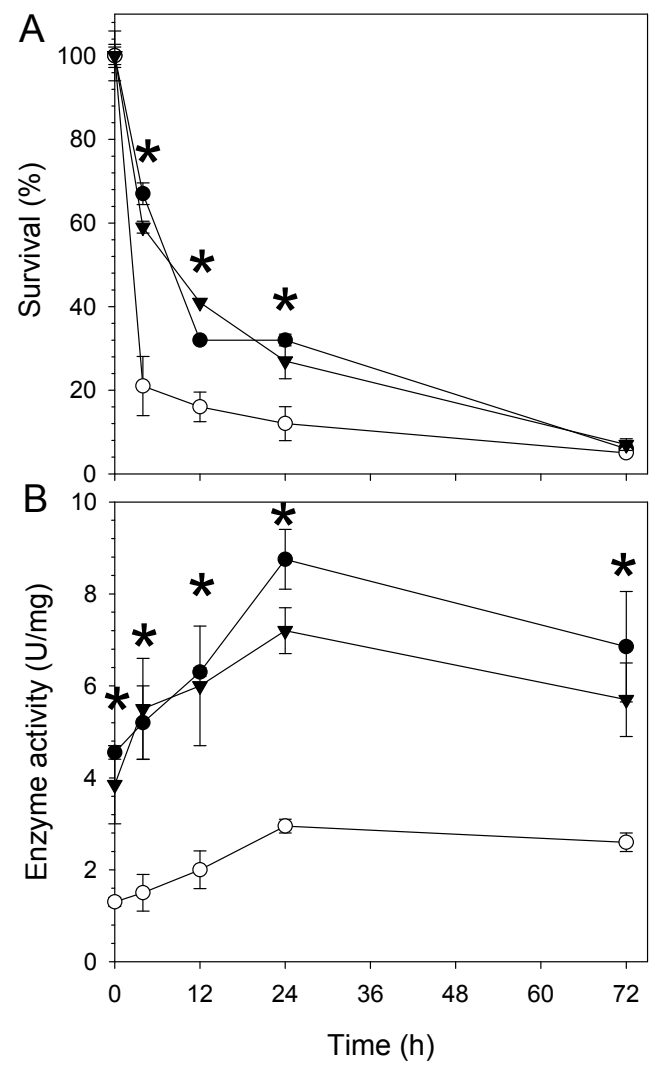

Figure 2. Effect of desiccation-induced stress on (A) survival of the three B. japonicum strains (wild type, ace A mutant WC2455, and aceA complemented strain WC2455-C) and (B) their ICL enzyme activities. One unit of ICL activity was defined as the amount of enzyme required to produce $1 \mu \mathrm{mol}$ of glyoxylate per min at $\mathrm{pH} 6.8$ and $30^{\circ} \mathrm{C}$. Symbols: -, wild type; $\circ$, WC2455; $\mathbf{\nabla}$, WC2455-C. Asterisks indicate significant differences between the wild type and mutant strains using $t$-test $(p<0.05)$. 
Desiccation stress is also likely to increase salinity in soil environments due to evaporation, and the increased salinity might consequently induce osmotic stress. Thus, we also tested the survival of B. japonicum under salt stress conditions. When grown with $70 \mathrm{mM} \mathrm{NaCl}$, wild type USDA110 showed a saturated cell density of $\sim 0.8 \mathrm{OD}_{600 \mathrm{~nm}}$, whereas the cell density of the aceA mutant did not exceed half of that of the wild type strain (Figure 3A). The ICL activity of the wild type and complemented strains (WC2455-C) was about 1.0 and $1.5 \mathrm{U} / \mathrm{mg}$ protein during late log phase and stationary phase, respectively, while that of WC2455 was $<2 \mathrm{U} / \mathrm{mg}$ protein (Figure 3B).
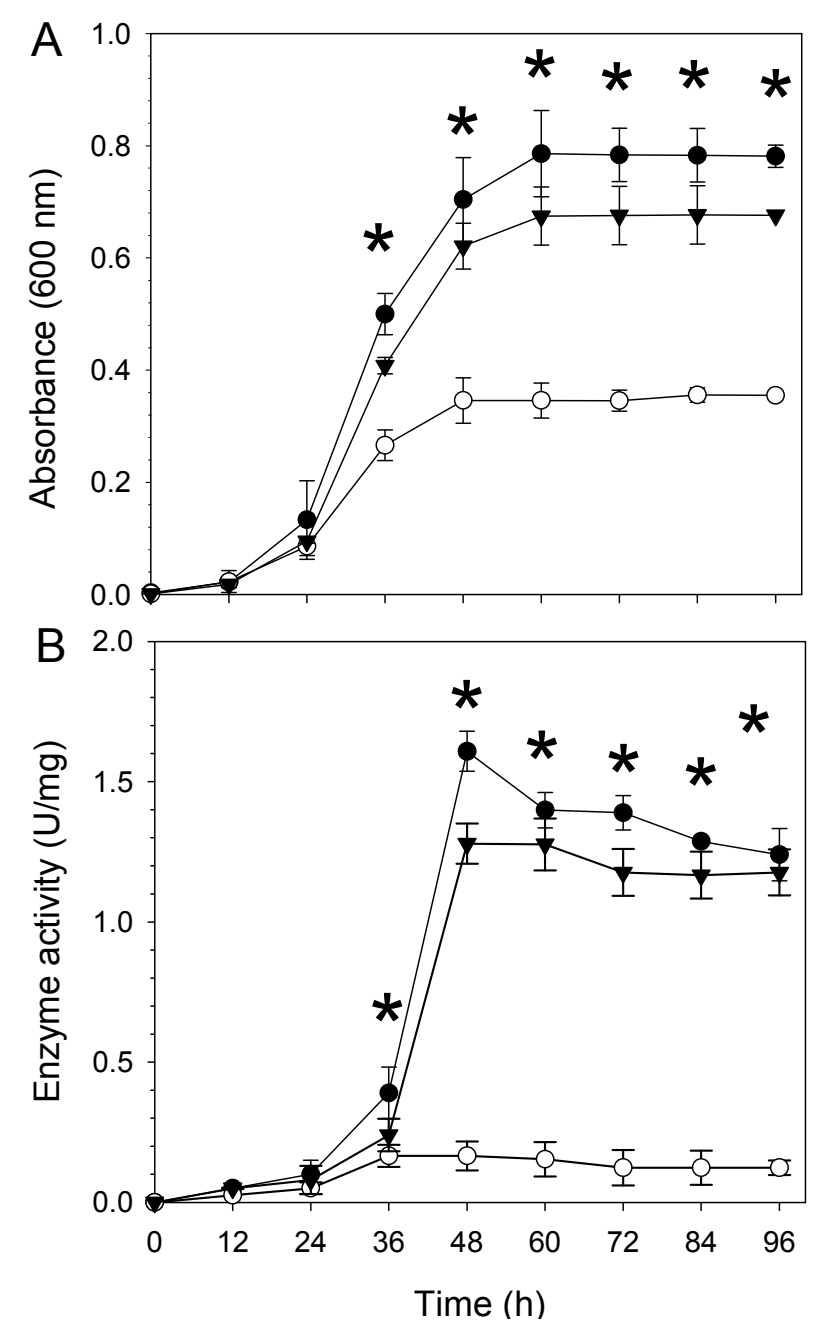

Figure 3. Effect of salt stress $(70 \mathrm{mM} \mathrm{NaCl})$ on $(\mathbf{A})$ growth of the three $B$. japonicum strains (wild type, aceA mutant WC2455, and aceA complemented strain WC2455-C) in AG medium and (B) their ICL enzyme activities. One unit of ICL activity was defined as the amount of enzyme required to produce $1 \mu \mathrm{mol}$ of glyoxylate per min at $\mathrm{pH} 6.8$ and $30{ }^{\circ} \mathrm{C}$. Symbols: •, wild type; O, WC2455; $\mathbf{\nabla}$, WC2455-C. Asterisks indicate significant differences between the wild type and the mutant using $t$-test $(p<0.05)$.

\subsection{Involvement of AceA in Response to Desiccation Stress Is Independent of the Glyoxylate Pathway} or the TCA Cycle

Since ICL is a key enzyme in the glyoxylate pathway, we hypothesized that the glyoxylate pathway or the related TCA cycle pathway may play a role in desiccation stress. Differential expression of 
genes involved in the glyoxylate pathway and TCA cycle was analyzed in wild type USDA110 and the ace $A$ mutant grown under desiccation stress by using qRT-PCR. Only aceA was highly expressed by desiccation stress in the wild type, whereas the expression of other genes was modest at best (Table 2). This result indicates that ICL is involved in the response to desiccation regardless of the glyoxylate or TCA cycles.

Table 2. Comparison of gene expression level changes against desiccation stress between wild type and WC2455 by qRT-PCR analysis.

\begin{tabular}{cccc}
\hline \multirow{2}{*}{ Locus (Gene) } & \multirow{2}{*}{ Gene Description $^{\text {a }}$} & \multicolumn{2}{c}{ Desiccation } \\
\cline { 3 - 4 } & & Wild Type & WC2455 \\
\hline bl10452 (sucA) & alpha-ketoglutarate dehydrogenase & 1.0 & 1.0 \\
bl10455 (sucC) & succinyl-CoA synthetase beta chain & -1.3 & -1.7 \\
bl11474 ( $g l c B)$ & malate synthase & -1.6 & 1.1 \\
blr0512 (sdhC) & succinate dehydrogenase cytochrome & 1.3 & 1.0 \\
blr2455 (ace $\mathrm{A})$ & isocitrate lyase & 148.0 & $\mathrm{ND}^{\mathrm{b}}$ \\
blr5747 (icd $\mathrm{A})$ & isocitrate dehydrogenase & -1.3 & 1.1 \\
blr6519 (fum $\mathrm{C})$ & fumarase C & 1.6 & 1.2 \\
\hline
\end{tabular}

${ }^{a}$ Gene descriptions represent third level annotations from the three-tiered functional level system of B. japonicum (www.kazusa.or.jp/rhizobase/Bradyrhizobium/cgi-bin/category_brady.cgi); ${ }^{\mathrm{b}}$ Not detected.

\subsection{Comparison of the Global Transcription Profiles in Wild Type and Mutant Strains}

Since strain WC2455 was significantly more sensitive to desiccation stress than wild type USDA110, genes related to expression of aceA may be involved in stress responses. To address this role of AceA, we performed genome-wide transcriptional analyses of wild type USDA110 and the ace $A$ mutant (WC2455) after $24 \mathrm{~h}$ of desiccation treatment $(27 \% \mathrm{RH})$.

Microarray analyses showed that 81 genes were differentially expressed, at a 1.5-fold cut-off (Supplemental Table S1). Of these 81 genes, 73 were up-regulated and eight were down-regulated. The upregulated genes were involved in the functional categories of cellular processes, energy metabolism, translation and transport, and binding proteins. Genes related to heat shock response, blr4637 and bll5219 ( $h s p D$ ), and seven chaperones encoded by blr4635 (groEL), blr4653 (dnaJ), blr5625 (groES), and blr5626 (groEL) were among the highly induced genes in the cellular processes category These genes are related to stress response defense mechanisms [18]. Also, several translation factors that are involved in ribosomal proteins were slightly induced (Table 3). To protect damaged cells from stress, translational machinery presumably associated with AceA could be enhanced. Similarly, more translation-related genes were highly induced in rich medium compared with minimal medium $[19,20]$. 
Table 3. Changes in expression of physiological process genes in desiccation-grown B. japonicum.

\begin{tabular}{|c|c|c|c|}
\hline Physiological Process & Locus (Gene ID) ${ }^{a}$ & Description $^{b}$ & Fold Induction \\
\hline \multirow{7}{*}{ Chaperones } & bs13986 (cspA) & cold shock protein & 1.7 \\
\hline & blr4637 & probable HspC2 heat shock protein & 1.6 \\
\hline & blr4635 (groEL) & chaperonin GroEL & 1.5 \\
\hline & blr4653 (dnaJ) & molecular chaperone DnaJ family & 1.7 \\
\hline & bl15219 (hspD) & small heat shock protein & 2.1 \\
\hline & blr5625 (groES) & $10 \mathrm{KD}$ chaperonin & 2.5 \\
\hline & blr5626 (groEL) & 60 KDA chaperonin & 2.1 \\
\hline \multirow{6}{*}{ Energy metabolism } & blr1656 & putative glycosyl hydrolase & 2.0 \\
\hline & bl13998 & $\begin{array}{l}\text { probable succinate-semialdehyde } \\
\text { dehydrogenase }\end{array}$ & 2.3 \\
\hline & blr4657 & beta-glucosidase & 1.6 \\
\hline & bl14784 & aldehyde dehydrogenase & 1.8 \\
\hline & blr6128 (cycB) & cytochrome c552 & 1.5 \\
\hline & blr7040 (napC) & cytochrome C-type protein & 2.1 \\
\hline $\begin{array}{l}\text { Heat shock } \\
\text { response systems }\end{array}$ & blr0678 & heat shock protein 70 & 2.0 \\
\hline \multirow{7}{*}{ Translation } & bl15377 (rpsK) & 30S ribosomal protein S11 & 1.8 \\
\hline & bl15381 (rplO) & 50S ribosomal protein L15 & 1.6 \\
\hline & bs15382 (rpmD) & $50 \mathrm{~S}$ ribosomal protein $\mathrm{L} 30$ & 1.6 \\
\hline & bs15391 (rpsQ) & $30 \mathrm{~S}$ ribosomal protein $\mathrm{S} 17$ & 1.5 \\
\hline & bs15392 (rpmC) & 50S ribosomal protein L29 & 1.8 \\
\hline & bl15397 (rplB) & 50S ribosomal protein L2 & 1.7 \\
\hline & bl15415 (rplK) & 50S ribosomal Protein L11 & 2.4 \\
\hline
\end{tabular}

a The differentially-expressed genes from each functional category were chosen with 1.5-fold cut-off and $p \leq 0.05 ;{ }^{b}$ Description (annotations) represents the third level from the three-tiered functional level system of B. japonicum (www.kazusa.or.jp/rhizobase/Bradyrhizobium/cgi-bin/category_brady.cgi).

\subsection{The Inactivation of AceA Results in Delayed Soybean Nodulation}

To evaluate the role of ace $A$ in the nodulation efficiency of $B$. japonicum, we first performed nodulation assays under hydroponic conditions using plant growth pouches. No significant difference was found in the number of nodules produced by wild type USDA110, the aceA mutant, or the complemented strain. They each formed approximately eight to nine nodules per plant. However, nodules formed by the aceA mutant were located most distantly from the initial root tip (RT) marked position compared to wild type USDA110 or the complemented strain, indicating that the mutant had a delayed nodulation response (Figure 4). This result suggests that AceA might facilitate the initiation of nodulation, but may be not essential for soybean nodulation by B. japonicum. While the ace A mutant showed a delayed nodulation response in growth pouches, no significant difference in the nitrogenase activity, as determined by the acetylene reduction assay, was found between wild type USDA110 and the ace A mutant (data not shown). 


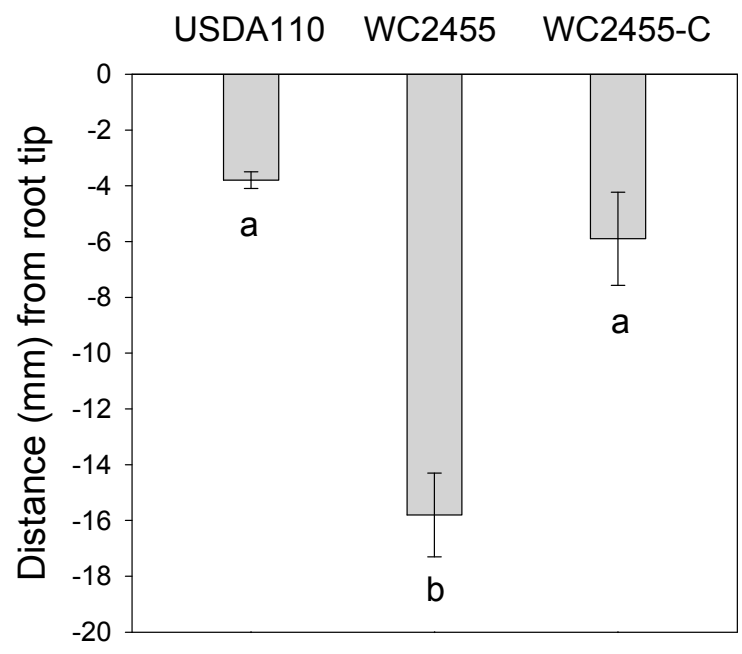

Figure 4. The effect of ace A gene on nodulation of $B$. japonicum. The average distance $(\mathrm{mm})$ of nodules form root tip (RT). Values are means \pm standard errors of the means from nine replications. The different letters below the bars indicate that the data are significantly different from each other $\left(p<0.05, \mathrm{JMP}^{\circledR} 8\right.$ software (SAS Institute Inc., Cary, NC, USA).

\section{Discussion}

In this study, we showed that ace $A$ is essential for the survival of $B$. japonicum under desiccation stress (Figure 2). There have been several lines of evidence supporting the hypothesis that ace $A$ may play an important role in bacterial resistance to various environmental stresses. The ace $A$ was induced by high salinity and under acid shock conditions in Shewanella sp. WP3 and M. tuberculosis, respectively [11,21]. Our previous study showed that $\mathrm{H}_{2} \mathrm{O}_{2}$-mediated oxidative stress also induced the expression of ace $A$ [6]. Likewise, it appears that environmental stresses also induce ICL activity in other bacteria. For example, the ICL activity in Pseudomonas was increased more than four-fold in an aluminum-rich environment [22]. Enhanced ICL activity was also observed in Cladosporium sphaerosperum in the presence of salt [23].

Inactivation of aceA did not affect the expression of genes related to either the TCA or glyoxylate cycles under desiccation stress conditions (Table 2). This indicates that aceA independently responds to desiccation stress, without interacting with substrates produced by enzymes in these other cycles. Although B. japonicum blr2455 was annotated as AceA, according to NCBI BLAST results, the protein specifically contains the ICL/PEPM superfamily conserved domain (cd00377), whose members catalyze either $\mathrm{P}-\mathrm{C}$ or $\mathrm{C}-\mathrm{C}$ bond formation/cleavage. Known members that belong to this conserved domain family are phosphoenolpyruvate mutase (PEPM), phosphonopyruvate hydrolase (PPH), carboxyPEP mutase (CPEP mutase), oxaloacetate hydrolase (OAH), isocitrate lyase (ICL), and 2-methylisocitrate lyase (MICL). Thus, the B. japonicum AceA appears to be a member of the canonical isocitrate lyase superfamily.

To determine if AceA regulates the expression of other genes, we compared the complete transcription profile of genes in the aceA mutant with that of wild type USDA110 during exposure to desiccation stress. Since transcriptome profiles were not much different between the ace $A$ mutant and wild type USDA110 under the tested conditions (only 81 genes were differentially expressed with 1.5-fold cut off), our data strongly suggests that AceA likely plays a limited role in overall gene regulation in B. japonicum. In addition, we compared these data to previous transcriptome profiles of 
the wild type USDA110 strain under desiccation-induced stress conditions [4]. Of the 73 up-regulated genes, 28 overlapped, including five translation-related genes (b115381, bs15382, bs15391, bs15392, and bll5397), five energy metabolism genes (bll3998, bll4784, bll5655, blr6128, and blr7040), four chaperonins (blr4637, blr4653, blr5625, and blr5626), one transport (bsr4636), one nitrogen fixation (blr2764), one regulatory gene (blr2475), and one chemotaxis (bll6865). Interestingly, there were 10 hypothetical function genes detected as overlapped genes. Although some genes were differentially expressed between the two different strains, the fold change was only modest (Table 3). While ace $A$ was down-regulated in the mutant strain, there was only a 2.7-fold change (Supplemental Table S1). This might be due to selection of our microarray probe for ace $A$, which was located almost at the beginning of the translational region for ace $A$, while the inactivated region of ace $A$ in the mutant was in the middle of the gene. Thus, a considerable amount of cDNA synthesized from partially transcribed mRNA for ace A might have hybridized to the probe.

Our results strongly suggest that ace $A$ may play both physiological and functional roles in bacterial stress responses. These observations also raise the possibility that ace $A$ in $B$. japonicum may independently play a protective role and has an enzymatic function in the TCA cycle in response to stress responses, such as $\mathrm{H}_{2} \mathrm{O}_{2}$-mediate oxidative stress and desiccation stress.

\section{Experimental Section}

\subsection{Bacterial Strains and Culture Conditions}

The bacterial strains and plasmids used in this study are shown in Table 4. The B. japonicum strains were grown aerobically at $30{ }^{\circ} \mathrm{C}$ on arabinose-gluconate (AG) medium [24]. The aceA mutant (WC2455) [25] and its complemented strain (WC2455-C) [6] were described previously. Escherichia coli strains were cultured on LB medium at $37{ }^{\circ} \mathrm{C}$, with shaking at $200 \mathrm{rpm}$. Antibiotics were used at the following concentrations, when needed: chloramphenicol, $30 \mu \mathrm{g} \cdot \mathrm{mL}^{-1}$; kanamycin, $150 \mu \mathrm{g} \cdot \mathrm{mL}^{-1}$; tetracycline $100 \mu \mathrm{g} \cdot \mathrm{mL}^{-1}$ for B. japonicum; and ampicillin, $50 \mu \mathrm{g} \cdot \mathrm{mL}^{-1}$; kanamycin, $50 \mu \mathrm{g} \cdot \mathrm{mL} L^{-1}$; and tetracycline, $50 \mu \mathrm{g} \cdot \mathrm{mL}^{-1}$ for E. coli.

\subsection{Desiccation Stress Assay}

The survivability of $B$. japonicum strains under desiccation-stress conditions was determined by the filter disk method as previously described [4]. A single colony of each B. japonicum strain (USDA110, WC2455, and WC2455-C) was inoculated into $5 \mathrm{~mL}$ of AG liquid medium, and cultures were grown to mid-exponential phase and transferred into fresh $\mathrm{AG}$ medium $(200 \mathrm{~mL})$ to $\mathrm{OD}_{600}=0.5$. The culture was divided into eight $25 \mathrm{~mL}$ aliquots and distributed into $50 \mathrm{~mL}$ conical tubes. Cultures were centrifuged at $10,000 \times \mathrm{g}$, washed, and resuspended in $25 \mathrm{~mL}$ minimal medium [26] to give $\mathrm{OD}_{600}=0.5$. The cell suspension was filtered onto sterilized $0.45 \mu \mathrm{m}$ cellulose nitrate membrane filters (47 mm diameter, Sterlitech, Kent, WA, USA). The membrane filters were aseptically placed at the bottom of perforated polystyrene petri dishes and immediately transferred into desiccators, which maintained $27 \%$ or $100 \%$ relative humidity $(\mathrm{RH})$, for desiccation or control conditions, respectively. After incubation in the dark at $30{ }^{\circ} \mathrm{C}$ for 4,24 , and $72 \mathrm{~h}$, viable counts of cells on membranes were determined by dilution plating on the agar medium. 
Table 4. Bacterial strains and plasmids used in this study.

\begin{tabular}{|c|c|c|}
\hline Strain or Plasmid & Genotypes, Relevant Characteristics & Source \\
\hline \multicolumn{3}{|c|}{ B. japonicum strains } \\
\hline USDA110 & wild type & $\begin{array}{c}\text { USDA-ARS } \\
\text { (Beltsville, MD, USA) }\end{array}$ \\
\hline WC2455 & ace $A:: \mathrm{Km}$ & {$[25]$} \\
\hline WC2455-C & WC2455 complemented strain & {$[6]$} \\
\hline \multicolumn{3}{|c|}{ E. coli strains } \\
\hline $\mathrm{DH} 5 \alpha$ & $\begin{array}{l}\text { supE44 } \Delta \text { lacU169 (ø 80lacZ } \Delta \text { M15) hsdR17 } \\
\text { recA1 endA1 gyrA96 thi-1 relA1 }\end{array}$ & {$[27]$} \\
\hline RIL(DE3) & $\operatorname{argU}(\mathrm{AGA}, \mathrm{AGG})$, ileY (AUA), leuW (CUA) & $\begin{array}{c}\text { Agilent } \\
\text { (La Jolla, CA, USA) }\end{array}$ \\
\hline \multicolumn{3}{|c|}{ Plasmids } \\
\hline pTE3 & complementing plasmid, $\mathrm{Tc}^{\mathrm{r}}$ & {$[28]$} \\
\hline pRK2073 & $\mathrm{RK} 2, \mathrm{Tra}^{+}, \mathrm{Sm}^{\mathrm{r}}$ & [29] \\
\hline pGEM-T easy & cloning vector & $\begin{array}{c}\text { Promega } \\
\text { (Madison, WI, USA) }\end{array}$ \\
\hline pQE2 & expression vector, $6 \mathrm{X}$ His tag, $\mathrm{T} 7$ promoter & $\begin{array}{c}\text { Qiagen } \\
\text { (Valencia, CA, USA) }\end{array}$ \\
\hline pGEM-T easy::ace $A$ & $\begin{array}{l}\text { pGEM T easy containing } 1.5 \mathrm{~kb} \text { fragment } \\
\text { including entire ace } A \text { gene }\end{array}$ & This study \\
\hline pTE-aceA & pTE3 containing $1.5 \mathrm{~kb}$ fragment of ace $A$ & This study \\
\hline pHis-aceA & pQE2 containing $1.8 \mathrm{~kb}$ fragment of aceA & This study \\
\hline
\end{tabular}

\subsection{Salt Stress Assay}

The $B$. japonicum cells were grown in AG medium supplemented with $70 \mathrm{mM} \mathrm{NaCl}$. Cell turbidity was measured and monitored at $\mathrm{OD}_{600}$ every $12 \mathrm{~h}$, until $96 \mathrm{~h}$. Control cultures were treated with sterilized distilled water $\left(\mathrm{ddH}_{2} \mathrm{O}\right)$. Each data point contained three biological replicates.

\subsection{RNA Isolation and Microarray Analysis}

Total RNA was extracted from B. japonicum cells by using the hot-phenol method as described previously [30]. Each $100 \mathrm{~mL}$ culture of B. japonicum strains USDA110 and WC2455 were grown at $30{ }^{\circ} \mathrm{C}$ until $\mathrm{OD}_{600}=0.5$. Cultures were divided into four $25 \mathrm{~mL}$ conical tubes, washed, resuspended in minimal medium, and filtered onto cellulose-nitrate membrane filters. Replicate membranes were transferred into desiccators at $27 \%$ or $100 \% \mathrm{RH}$, and incubated at $30{ }^{\circ} \mathrm{C}$ for 0 and $24 \mathrm{~h}$. Cells were recovered from membrane by agitation in $10 \mathrm{~mL}$ of medium, centrifuged at $8000 \times \mathrm{g}$, and washed in minimal medium. All extracted RNA samples were further purified using RNeasy Mini Kits (Qiagen, Germantown, MD, USA) for microarray and quantitative reverse transcription PCR (qRT-PCR) experiments. The synthesis of cDNA synthesis, labeling with $\mathrm{Cy} 3$ and $\mathrm{Cy} 5$, and microarray hybridizations were performed as described previously [19]. All microarray experiments were performed with three biological replicates for each condition. The raw microarray data from this study are deposited in the NCBI Gene Expression Omnibus (GEO) database under accession number GSE69999 (http://www.ncbi.nlm.nih.gov/geo/query/acc.cgi?acc=GSE69999). 


\section{5. $q R T-P C R$ Analysis}

The qRT-PCR was performed according to methods described previously [19]. Gene specific primers used for qRT-PCR are listed in Table 5. For normalization of the qRT-PCR data, the expression value of each gene was calculated relative to parA gene (bll0631), encoding the chromosome-partitioning protein. All qRT-PCR experiments were performed with three biological replicates for each condition.

Table 5. Primers used for qRT-PCR analysis.

\begin{tabular}{|c|c|c|}
\hline Gene & Forward Sequence 5'-3' & Reverse Sequence 5'-3' \\
\hline bl10452 & CGGCATCGACGACATCTACCTGAT & TCCAGATAGGGCTCGATGAAGTGC \\
\hline bl10455 & GAGACAGAGGAAGACGCCAAGGAA & GCCATGCCGTAGAGCTTGATGATG \\
\hline bl11474 & GCCTCCAAGCGCATCATGTTCATC & CATGTCGACGTTCCAGTCCTCGTA \\
\hline blr0512 & TTCAAGGCCAATGAGCGCGAAG & ACGATCCAGATCAGCACCGTCA \\
\hline blr2455 & GGCGACCAGTACAACAGCTT & GTCTCGATCCAGAGCAGGTC \\
\hline blr5747 & TGTCGACCAAGAACACCATCCTCA & TAGTTCTTGCAGGCCCAGACATAGC \\
\hline blr6519 & GGCCATTTCGAGCTCAACGTCTAC & CTGACGCAATGTTCGGTGAAGGAG \\
\hline bl10631 & TCAACCTTCTGACGGTGAACGC & TGCAGCAATTGCGACAGACCTT \\
\hline
\end{tabular}

\subsection{ICL Enzyme Assay}

B. japonicum cells recovered after desiccation or osmotic treatments were harvested by centrifugation for $5 \mathrm{~min}$ at $8000 \times \mathrm{g}$, and cell pellets were washed in $50 \mathrm{mM}$ Tris-sodium EDTA (TNE) buffer ( $\mathrm{pH}$ 7.0). Cells were resuspended in $1 \mathrm{~mL}$ breaking buffer $(20 \mathrm{mM}$ TNE buffer ( $\mathrm{pH} 7.0)$, $100 \mathrm{mM} \mathrm{NaCl}, 5 \mathrm{mM} \mathrm{MgCl} 2,0.4 \mathrm{mM}$ EDTA, $1.5 \mathrm{mM}$ DTT and 2\% (wt/v) glycerol) [31] and were subsequently sonicated for $1 \mathrm{~min}$. The cell pellet was removed by centrifugation at $8000 \times g$ for $5 \mathrm{~min}$. The isocitrate lyase assay was performed according to Sigma-Aldrich's protocol and the method of Chell [32], with some modifications. A $0.1 \mathrm{~mL}$ aliquot of freshly prepared cell-free supernatant was added to the reaction mixture and incubated for $5 \mathrm{~min}$ at $30^{\circ} \mathrm{C}$. The reaction mixture contained $30 \mathrm{mM}$ imidazole buffer ( $\mathrm{pH}$ 6.8), $5 \mathrm{mM} \mathrm{MgCl}_{2}, 1 \mathrm{mM}$ EDTA, $4 \mathrm{mM}$ phenylhydrazine hydrochloride (Sigma-Aldrich, St. Louis, MO, USA), and $1 \mathrm{mM}$ DL-isocitric acid (Sigma-Aldrich, St. Louis, MO, USA). The enzyme activity was determined by measuring absorbance at $340 \mathrm{~nm}$. One unit $(\mathrm{U})$ of the ICL activity was defined as the amount of substrate consumed to produce $1 \mu \mathrm{mol}$ of glyoxylate per min at $30^{\circ} \mathrm{C}$.

\subsection{Construction of $p Q E 2::$ AceA Strain}

A $1.8 \mathrm{~kb}$ DNA fragment, including the ace $A$ coding region, was amplified by PCR using primers aceA_fw (5'-TATACATATGCAATTACATG ACATCACCAATAAA-3') and aceA_rv (5'-ATAT AAGCTTTTAGCCGAACTGGTTCATCGT-3'), where the underlined sequences indicate $N d e I$ and HindIII restriction enzyme linkers for $a c e A_{-}$fw and $a c e A_{-}$rv, respectively. The three nucleotides in bold in $a c e A$ fw represent the codon for glutamine placed to avoid a frame shift of the ace $A$ coding region. The PCR product was sequenced to confirm the aceA coding region and cloned into $\mathrm{pQE} 2$ 
(Qiagen Science, Maryland, MD, USA) to express His6-tagged AceA in E. coli RIL(DE3) (Agilent, La Jolla, CA, USA). The resulting plasmid was named pHis-aceA (Table 4).

\subsection{Purification of AceA Protein}

The AceA was purified by the His-tag method. A single colony of E. coli RIL(DE3) containing pHis-aceA was grown overnight in $5 \mathrm{~mL}$ LB medium supplemented with ampicillin $\left(50 \mu \mathrm{g} \cdot \mathrm{mL}^{-1}\right)$ and gentamycin $\left(20 \mu \mathrm{g} \cdot \mathrm{mL}^{-1}\right)$. The overnight culture was diluted $(1 \% v / v)$ into $50 \mathrm{~mL} \mathrm{LB}$ medium without antibiotics, and grown for $3 \mathrm{~h}$ at $30{ }^{\circ} \mathrm{C}$ with shaking at $200 \mathrm{rpm}$. The subculture was immediately transferred into a pre-chilled 50-mL Erlenmeyer flask, and expression of aceA was induced by adding IPTG to a final concentration of $0.1 \mathrm{mM}$. After induction for $36 \mathrm{~h}$ at $10{ }^{\circ} \mathrm{C}$ with shaking, cells were harvested by centrifugation at $4000 \times g$ for $20 \mathrm{~min}$. The cell pellet was resuspended in $3 \mathrm{~mL}$ lysis buffer ( $50 \mathrm{mM} \mathrm{NaH}_{2} \mathrm{PO}_{4}, 300 \mathrm{mM} \mathrm{NaCl}$ and $10 \mathrm{mM}$ imidazole; $\mathrm{pH} \mathrm{8.0)}$ and stored at $-80^{\circ} \mathrm{C}$ until used.

After thawing the cell suspension at $4{ }^{\circ} \mathrm{C}$, cells were lysed by six repetitions of sonication on ice for $10 \mathrm{~s}$ with 10 -s pause at each interval. The lysate was centrifuged for $3 \mathrm{~min}$ at $4000 \times g$ at $4{ }^{\circ} \mathrm{C}$ and the supernatant was loaded onto a 5-mL Ni-NTA column equilibrated with lysis buffer. The resin was washed twice with wash buffer (lysis buffer containing $20 \mathrm{mM}$ imidazole instead of $10 \mathrm{mM}$ imidazole) and the protein was eluted in $5 \mathrm{~mL}$ of elution buffer (wash buffer containing $250 \mathrm{mM}$ imidazole instead of $20 \mathrm{mM}$ imidazole). The eluate was stored as a $10 \%$ glycerol solution at $-80{ }^{\circ} \mathrm{C}$ until used for further experiments. The ICL activity of AceA was measured by the method described above, but using the purified protein instead of the cell-free extract.

\subsection{Nodulation Assay}

Soybean nodulation assays were done in plastic growth pouches (Mega International, St. Paul, MN, USA) as described previously [33]. Soybean seeds were sterilized by washing in $20 \%$ solution of commercially available bleach for $10 \mathrm{~min}$, rinsed 3 times with sterile distilled water, washed in $0.01 \mathrm{~N}$ $\mathrm{HCl}$ for $10 \mathrm{~min}$, and rinsed 3 times with sterile distilled water. Sterilized soybean seeds were placed onto the surface of pre-soaked Whatman filter paper in petri dishes and germinated for 3 days in the dark at room temperature. Three seedlings were aseptically transferred into each autoclaved growth pouch and the position of root tip (RT) was marked on the surface of the growth pouch [34]. Each plant was inoculated with $1 \mathrm{~mL}$ of cell suspension of the $B$. japonicum culture prepared by harvesting at mid-log phase, washing with half strength B\&D medium (no nitrogen source) [35], and resuspending in the same medium to give $\mathrm{OD}_{600}=0.1\left(\mathrm{ca} .10^{8}\right.$ cells $\left./ \mathrm{mL}\right)$. The plants were grown in a plant growth chamber at $26^{\circ} \mathrm{C}$ with 15 h-day and 9 h-night cycles. Soybean plants were watered with $10 \mathrm{~mL}$ of half strength B\&D medium for 4 weeks until they were harvested for the following analysis: The number of nodules on the primary root was counted and the distance of the nodules was measured from the RT mark.

\section{Conclusions}

Our findings show the physiological and functional role of $B$. japonicum ICL under desiccation-induced stress conditions. These observations raise the dual function possibility of ace $A$ gene in $B$. japonicum: 
(i) AceA protein independently plays a protective role against environmental factors such as desiccation and salt stresses and (ii) has an enzymatic function in the glyoxylate pathway, a bypass of the TCA cycle, to catalyze the conversion of isocitrate to succinate and glyoxylate.

\section{Supplementary Materials}

Supplementary materials can be found at http://www.mdpi.com/1422-0067/16/07/16695/s1.

\section{Acknowledgments}

This research was supported by a Research Enhancement Program (REP) grant from the University of Texas-Arlington. We thank John Ferguson and Ping Wang for help with assays.

\section{Author Contributions}

Jeong-Min Jeon, Michael J. Sadowsky and Woo-Suk Chang designed the experiment; Jeong-Min Jeon, Hae-In Lee and Masayuki Sugawara conducted the experiment; Jeong-Min Jeon, Hae-In Lee, Michael J. Sadowsky and Woo-Suk Chang wrote the manuscript.

\section{Conflicts of Interest}

The authors declare no conflict of interest.

\section{References}

1. Bashan, Y. Inoculants of plant growth-promoting bacteria for use in agriculture. Biotechnol. Adv. 1998, 16, 729-770.

2. Mary, P.; Ochin, D.; Tailliez, R. Rates of drying and survival of Rhizobium meliloti strains during storage at different relative humidities. Appl. Environ. Microbiol. 1985, 50, 207-211.

3. Streeter, J.G. Factors affecting the survival of Bradyrhizobium applied in liquid cultures to soya bean [Glycine $\max$ (L.) Merr.] seeds. J. Appl. Microbiol. 2007, 103, 1282-1290.

4. Cytryn, E.J.; Sangurdekar, D.P.; Streeter, J.G.; Franck, W.L.; Chang, W.-S.; Stacey, G.; Emerich, D.W.; Joshi, T.; Xu, D.; Sadowsky, M.J. Transcriptional and physiological responses of Bradyrhizobium japonicum to desiccation-induced stress. J. Bacteriol. 2007, 189, 6751-6762.

5. Donati, A.J.; Jeon, J.M.; Sangurdekar, D.; So, J.-S.; Chang, W.-S. Genome-wide transcriptional and physiological responses of Bradyrhizobium japonicum to paraquat-mediated oxidative stress. Appl. Environ. Microbiol. 2011, 77, 3633-3643.

6. Jeon, J.M.; Lee, H.-I.; Donati, A.J.; So, J.-S.; Emerich, D.W.; Woo-Suk Chang, W.-S.C. Whole-genome expression profiling of Bradyrhizobium japonicum in response to hydrogen peroxide. Mol. Plant Microbe Interact. 2011, 24, 1472-1481.

7. Fang, F.C.; Libby, S.J.; Castor, M.E.; Fung, A.M. Isocitrate lyase (AceA) is required for Salmonella persistence but not for acute lethal infection in mice. Infect. Immun. 2005, 73, 2547-2549.

8. Lorenz, M.C.; Fink, G.R. Life and death in a macrophage: Role of the glyoxylate cycle in virulence. Eukaryot. Cell 2002, 1, 657-662. 
9. Dunn, M. Tricarboxylic acid cycle and anaplerotic enzymes in rhizobia. FEMS Microbiol. Rev. 1998, 22, 105-123.

10. Geddes, B.A.; Oresnik, I.J. Physiology, genetics, and biochemistry of carbon metabolism in the alphaproteobacterium Sinorhizobium meliloti. Can. J. Microbiol. 2014, 60, 491-507.

11. Li, S.; Xiao, X.; Li, J.; Luo, J.; Wang, F. Identification of genes regulated by changing salinity in the deep-sea bacterium Shewanella sp. WP3 using RNA arbitrarily primed PCR. Extremophiles 2006, 10, 97-104.

12. Watanabe, S.; Yamaoka, N.; Takada, Y.; Fukunaga, N. The cold-inducible icl gene encoding thermolabile isocitrate lyase of a psychrophilic bacterium, Colwellia maris. Microbiology 2002, 148, 2579-2589.

13. Dunn, M.F.; Ramirez-Trujillo, J.A.; Hernandez-Lucas, I. Major roles of isocitrate lyase and malate synthase in bacterial and fungal pathogenesis. Microbiology 2009, 155, 3166-3175.

14. Munoz-Elias, E.J.; McKinney, J.D. Mycobacterium tuberculosis isocitrate lyases 1 and 2 are jointly required for in vivo growth and virulence. Nat. Med. 2005, 11, 638-644.

15. Sharma, V.; Sharma, S.; Hoener, Z.U.; Bentrup, K.; McKinney, J.D.; Russell, D.G.; Sacchettini, J.C. Structure of isocitrate lyase, a persistence factor of Mycobacterium tuberculosis. Nat. Struct. Biol. 2000, 7, 663-668.

16. Idnurm, A.; Howlett, B.J. Isocitrate lyase is essential for pathogenicity of the fungus Leptosphaeria maculans to canola (Brassica napus). Eukaryot. Cell 2002, 1, 719-724.

17. Pradheep, S.A.; Narayanan, S.; Vasan, S.K.; Narayanan, P.R. Cloning and expression of aceA gene encoding isocitrate lyase from Mycobacterium tuberculosis. Curr. Sci. 2000, 79, 1585-1588.

18. Nollen, E.A.; Morimoto, R.I. Chaperoning signaling pathways: Molecular chaperones as stress-sensing "heat shock" proteins. J. Cell Sci. 2002, 115, 2809-2816.

19. Chang, W.-S.; Franck, W.L.; Cytryn, E.; Jeong, S.; Joshi, T.; Emerich, D.W.; Sadowsky, M.J.; $\mathrm{Xu}, \mathrm{D}$; Stacey, G. An oligonucleotide microarray resource for transcriptional profiling of Bradyrhizobium japonicum. Mol. Plant Microbe Interact. 2007, 20, 1298-1307.

20. Tao, H.; Bausch, C.; Richmond, C.; Blattner, F.R.; Conway, T. Functional genomics: Expression analysis of Escherichia coli growing on minimal and rich media. J. Bacteriol. 1999, 181, 6425-6440.

21. Fisher, M.A.; Plikaytis, B.B.; Shinnick, T.M. Microarray analysis of the Mycobacterium tuberculosis transcriptional response to the acidic conditions found in phagosomes. J. Bacteriol. 2002, 184, 4025-4032.

22. Hamel, R.; Appanna, V.D.; Viswanatha, T.; Puiseux-Dao, S. Overexpression of isocitrate lyase is an important strategy in the survival of Pseudomonas fluorescens exposed to aluminum. Biochem. Biophys. Res. Commun. 2004, 317, 1189-1194.

23. Karlekar, K.; Parekh, T.V.; Chhatpar, H.S. Salt mediated changes in some enzymes of carbohydrate-metabolism in halotolerant Cladosporium sphaerospermum. J. Biosci. 1985, 9, 197-201.

24. Sadowsky, M.J.; Tully, R.E.; Cregan, P.B.; Keyser, H.H. Genetic diversity in Bradyrhizobium japonicum serogroup 123 and its relation to genotype-specific nodulation of soybean. Appl. Environ. Microbiol. 1987, 53, 2624-2630. 
25. Franck, W.L.; Chang, W.-S.; Qiu, J.; Sugawara, M.; Sadowsky, M.J.; Stephanie, A.; Smith, S.A.S.; Gary Stacey, G.S. Whole-genome transcriptional profiling of Bradyrhizobium japonicum during chemoautotrophic growth. J. Bacteriol. 2008, 190, 6697-6705.

26. Bergersen, F.J. The growth of rhizobia in synthetic media. Aust. J. Biol. Sci. 1961, 14, 349-360.

27. Sambrook, J.; Fritsch, E.F.; Maniatis, T. Molecular Cloning: A Laboratory Manual; Cold Spring Harbor Laboratory: Cold Spring Harbor, NY, USA, 1989; Volume 3, p. A.10.

28. Egelhoff, T.T.; Fisher, R.F.; Jacobs, T.W.; Mulligan, J.T.; Long, S.R. Nucleotide sequence of Rhizobium meliloti 1021 nodulation genes: nodD is read divergently from nodABC. DNA 1985, 4, 241-248.

29. Leong, S.A.; Ditta, G.S.; Helinski, D.R. Heme biosynthesis in Rhizobium. Identification of a cloned gene coding for delta-aminolevulinic acid synthetase from Rhizobium meliloti. J. Biol. Chem. 1982, 257, 8724-8730.

30. Bittner, M.; Butow, R.; DeRisi, J.; Diehn, M.; Eberwine, J.; Epstein, C.B.; Glynne, R.; Grimmond, S.; Ideker, T.; Kacharmina, J.E.; et al. Expression analysis of RNA. In DNA Microarrays; Bowtell, D., Sambrook, J., Eds.; Cold Spring Harbor Laboratory: Cold Spring Harbor, NY, USA, 2003; pp. 101-288.

31. Green, L.S.; Karr, D.B.; Emerich, D.W. Isocitrate dehydrogenase and glyoxylate cycle enzyme activities in Bradyrhizobium japonicum under various growth conditions. Arch. Microbiol. 1998, 169, 445-451.

32. Chell, R.M.; Sundaram, T.K.; Wilkinson, A.E. Isolation and characterization of isocitrate lyase from a thermophilic Bacillus sp. Biochem. J. 1978, 173, 165-177.

33. Lee, H.-I.; Lee, J.-H.; Park, K.-H.; Sangurdekar, D.; Chang, W.-S. Effect of soybean coumestrol on Bradyrhizobium japonicum nodulation ability, biofilm formation, and transcriptional profile. Appl. Environ. Microbiol. 2012, 78, 2896-2903.

34. Donati, A.J.; Lee, H.-I.; Leveau, J.H.; Chang, W.-S. Effects of indole-3-acetic acid on the transcriptional activities and stress tolerance of Bradyrhizobium japonicum. PLoS ONE 2013, 8, e76559.

35. Broughton, W.J.; Dilworth, M.J. Control of leghaemoglobin synthesis in snake beans. Biochem. J. 1971, 125, 1075-1080.

(C) 2015 by the authors; licensee MDPI, Basel, Switzerland. This article is an open access article distributed under the terms and conditions of the Creative Commons Attribution license (http://creativecommons.org/licenses/by/4.0/). 